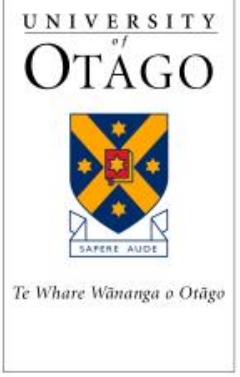

ISSN 0111-1760 (Print) ISSN 1178-2293 (Online)

University of Otago Economics Discussion Papers

No. 0805

School of Business

Unlimited Future, Unlimited Possibilities

Te Kura Pakihi

26 May 2008

\title{
Estimating quarterly GDP Data for the South Pacific Island Nations
}

\author{
Willie Lahari, Alfred A. Haug ${ }^{*}$ and Arlene Garces-Ozanne \\ Department of Economics \\ University of Otago
}

${ }^{*}$ Corresponding author:

Prof Alfred A. Haug

Department of Economics

University of Otago

PO Box 56

Dunedin 9054

NEW ZEALAND

E-mail:ahaug@business.otago.ac.nz

Telephone: 6434795636

Fax: 6434798174 


\begin{abstract}
Time series analyses generally rely on having a relatively high frequency of consistent and reliable data to work with. However for many of the South Pacific Island Nations (SPINS), data on major macroeconomic series, like GDP, are typically available only annually from the early 1980s. This paper empirically estimates quarterly GDP data from annual series using the approach of Abeysinghe and Rajaguru (2004), following the basic framework of Chow and Lin (1971), Fernandez (1981) and Litterman (1983). We link the available annual GDP series for a select group of SPINS with GDP-related series (predictor variables) that are available quarterly. We deem that our quarterly estimates of GDP are more consistent and reliable compared to estimates obtained through less sophisticated methods of univariate interpolation.
\end{abstract}

JEL codes: C82; E00

Keywords: Quarterly GDP; disaggregation of time series; South Pacific Island Nations. 
Empirical studies assessing the economic performance of South Pacific Island Nations (SPINS) have often produced mixed results. ${ }^{1}$ A primary reason for this is related to the lack of consistent, reliable and comparable data for these countries, which prevents a comprehensive analysis of these countries' economic growth experiences and business cycles. During the Pacific Island Forum Economic Ministers Meeting (FEMM, 2000) and the regional Heads of Statistics and Planning Meeting (Secretariat of the Pacific Community, 2003, 2005, 2007) there was consensus that the issue of the non-availability of reliable, timely and quality economic and social statistics was a major constraint to policy making and planning in the region. Moreover, time series analyses suffer from low power and accuracy because of the use of a relatively short span of time series data for major economic indicators, like GDP. Haug (2002), however, shows that disaggregation of data (or, equivalently, higher frequency of observation or less temporal aggregation) can add power to tests (e.g., tests for cointegration), even if the span is kept fixed.

This paper seeks to address one of the shortcomings of data for selected SPINS by deriving quarterly estimates of real GDP for Fiji, Papua New Guinea (PNG), Samoa, the Solomon Islands, Tonga and Vanuatu. We use the basic methodology of Chow and Lin (1971) for estimating quarterly GDP figures from GDP-related quarterly series and annual GDP. This basic method has been modified through the years by Fernandez (1981) and Litterman (1983) to deal with the nonstationary characteristics of the data, and recently applied by Abeysinghe and Rajaguru (2004) to derive quarterly estimates of GDP for China and the ASEAN4 countries (Indonesia, Malaysia, the Philippines and Thailand). Others, like Hall and McDermott (2007) for New Zealand, have also applied the Chow-Lin-based approach to disaggregating data. $^{2}$

The remainder of this paper is organised as follows. Section 2 provides an overview of the basic methodology for estimating quarterly series from related series. Section 3

\footnotetext{
${ }^{1}$ See for instance Briguglio, 1995; Armstrong et al., 1998; Easterly and Kraay, 2000; and Armstrong and Read, 2002, among many others.

${ }^{2}$ Alternative methods for disaggregation have been suggested by Moauro and Savio (2005), among others, using the Kalman filter. However, in practice, the Chow-Lin-based methodology is the most widely used.
} 
describes the application of the methodology to derive quarterly real GDP estimates for SPINS, following the approach of Abeysinghe and Rajaguru (2004). Sections 4 and 5 detail the steps taken to convert the derived nominal quarterly series to real quarterly series and to ascertain the quality of the derived real quarterly series. Section 6 presents some concluding remarks.

\section{$2 \quad$ Disaggregating time series}

Chow and Lin (1971) provide a systematic method of estimating monthly time series data from quarterly data. Essentially, the Chow-Lin method identifies a relationship between the quarterly series of a variable, say GDP, and the monthly series of related variables (e.g., components of GDP like exports) to derive monthly estimates for GDP. With some modifications, the Chow-Lin method can be applied to the estimation of quarterly series from annual series.

We assume that the $T$ observations in the quarterly series of GDP, $y_{q}$, are related to the $T$ observations on quarterly GDP-related variables, $X_{q}$, based on a regression of the form

$$
y_{q}=X_{q} \beta_{q}+\hat{u}_{q}
$$

where $y_{q}$ is $(T \times 1)$ and $X_{q}$ is $(T \times k)$. The error term follows a stationary first-order autoregression $u_{q, t}=\rho_{q} u_{q, t-1}+e_{q, t}$ for $t=1, \ldots T$, with $e_{q, t}$ having zero mean and a covariance matrix of $\sigma_{e}^{2} I_{T}$.

The Chow and Lin (1971) equation that disaggregates $n$ annual GDP estimates to $4 n=$ $T$ quarterly estimates is expressed as:

$$
\hat{y}_{q}=X_{q} \hat{\beta}_{a}+V_{q} C^{\prime}\left(C V_{q} C^{\prime}\right)^{-1} \hat{u}_{a}
$$

Where $\beta_{a}$ is estimated as:

$$
\hat{\beta}_{a}=\left[X_{q}^{\prime} C^{\prime}\left(C V_{q} C^{\prime}\right)^{-1} C X_{q}\right]^{-1} X_{q}^{\prime} C^{\prime}\left(C V_{q} C^{\prime}\right)^{-1} y_{a}
$$

and 


$$
C=\left[\begin{array}{lllllllllllll}
1 & 1 & 1 & 1 & 0 & 0 & 0 & 0 & \cdots & 0 & 0 & 0 & 0 \\
0 & 0 & 0 & 0 & 1 & 1 & 1 & 1 & \cdots & . & . & . & . \\
. & . & . & . & . & . & . & . & \cdots & 0 & 0 & 0 & 0 \\
0 & 0 & 0 & 0 & . & . & . & . & \cdots & 1 & 1 & 1 & 1
\end{array}\right]
$$

The $(4 n \times 1)$ vector of disaggregated quarterly GDP estimates is represented by $\hat{y}_{q}$. $X_{q}$ is a $(4 n \times k)$ matrix, ignoring the constant term for now, of $k$ predictor (GDPrelated) variables and $\hat{\beta}_{a}$ is a $(k \times 1)$ vector of generalised least squares (GLS) estimates derived from annual data. $V_{q}$ is the covariance matrix $(4 n \times 4 n)$ of the quarterly errors, $u_{q, t}$, and $\hat{u}_{a}=y_{a}-X_{a} \hat{\beta}_{a}$ is a $(n \times 1)$ vector of residuals from an annual regression of GDP on predictor variables $\left(X_{a}=C X_{q}\right) . C$ is an $(n \times 4 n)$ averaging matrix if multiplied by 0.25 or an aggregation matrix as presented in equation (4), and $y_{a}$ represents the observed $n \times 1$ vector of annual GDP figures.

Fernandez (1981) and Litterman (1983), however, point out that this method is appropriate only when the error process is covariance stationary, and propose alternatives that correct for this shortcoming in the Chow-Lin method. Fernandez suggests that if the series have unit roots, i.e., they are integrated of order 1, denoted $I(1)$, the series need to be transformed first (by taking first differences) to yield series that are stationary. Fernandez assumes that $\rho_{q}=1$, which implies a regression based on first differences. Litterman on the other hand generalises the Fernandez approach by pre-filtering the data in order to remove serial correlation in the errors. That is, autocorrelation is also incorporated in the estimation procedure. Since economic series are usually characterised as integrated processes, it is imperative to examine cointegrating relationships first between the variable of interest and its related variables, and then apply the Chow-Lin procedure with serial correlation adjustment as needed, instead of first-differencing. If cointegration is present, it implies a process in first differences with an error-correction term added in the model. This implies that a specification in first differences alone is misspecified when there is cointegration.

Following the basic methodology of Chow and Lin (1971) and the extensions proposed by Fernandez (1981) and Litterman (1983), Abeysinghe and Rajaguru (2004) derive quarterly real GDP estimates for China and several ASEAN countries. In a similar way, we adopt this methodology to derive the quarterly GDP estimates for 
selected SPINS. Based on Litterman's extensions to the basic Chow-Lin method, we assume that $u_{q, t}=\rho_{q} u_{q, t-1}+e_{q, t}$ with $e_{t} \sim$ iid $\left(0, \sigma_{e}^{2}\right)$ and substitute $V_{q}$ with (D'H'HD) ${ }^{-1}$ :

$$
D=\left[\begin{array}{cccccc}
1 & 0 & 0 & \cdots & 0 & 0 \\
-1 & 1 & 0 & \cdots & 0 & 0 \\
0 & -1 & 1 & \cdots & 0 & 0 \\
. & . & . & \cdots & . & . \\
0 & 0 & 0 & \cdots & -1 & 1
\end{array}\right]_{4 n \times 4 n} \text { and } H=\left[\begin{array}{cccccc}
1 & 0 & 0 & \cdots & 0 & 0 \\
-\rho_{q} & 1 & 0 & \cdots & 0 & 0 \\
0 & -\rho_{q} & 1 & \cdots & 0 & 0 \\
\cdot & \cdot & . & \cdots & . & \cdot \\
0 & 0 & 0 & \cdots & -\rho_{q} & 1
\end{array}\right]_{4 n \times 4 n}
$$

The calculation of $\rho_{q}$ from the annual $\rho_{a}$ is based on the relation: ${ }^{3}$

$\rho_{a}=\frac{\rho_{q}^{10}+4 \rho_{q}^{9}+10 \rho_{q}^{8}+20 \rho_{q}^{7}+31 \rho_{q}^{6}+40_{q}^{5}+44 \rho_{q}^{4}+40 \rho_{q}^{3}+32 \rho_{q}^{2}+24 \rho_{q}+10}{2 \rho_{q}^{6}+8 \rho_{q}^{5}+20 \rho_{q}^{4}+40 \rho_{q}^{3}+62 \rho_{q}^{2}+80 \rho_{q}+44}$

By setting $\mathrm{H}=\mathrm{I}$, we get the Fernandez (1981) case which involves first-differencing the series. When $\mathrm{D}=\mathrm{I}$, the model becomes the Chow-Lin case with $\mathrm{AR}(1)$ errors, and it is then preferable to equate the first element of $\mathrm{H}$ to $\sqrt{1-\rho^{2}}$. Finally, by setting $\mathrm{D}=\mathrm{H}=\mathrm{I}$, we arrive at the basic Chow-Lin case with white noise errors.

\section{Estimating quarterly GDP series for the SPINS}

In deriving quarterly GDP estimates for the SPINS, we initially test for unit roots of each series and also for cointegration between the annual GDP variable and associated annual predictor variables. Marcellino (1999) proves that the integration and cointegration properties are invariant across different levels of aggregation of time series. This means that if the annual series have a unit root, so will the quarterly series. It also means that if two annual series are cointegrated, so will the quarterly series be cointegrated. Note that the Chow-Lin decomposition generally works well with annual GDP regressed on two or more quarterly predictor variables in order to derive robust and efficient quarterly estimates. The computer software EViews 6.1 is used for all unit root and cointegration tests. Gauss 8.1 is used for all transformations of annual to quarterly data.

\footnotetext{
${ }^{3}$ A real solution for $\rho_{q}$ requires $\hat{\rho}_{a}>0.166$. See Abeysinghe and Rajaguru (2004) for details.
} 


\subsection{Determining the predictor variables}

The derivation of quarterly real GDP estimates involves finding relevant real predictor variables. However, there were much fewer available data on real variables than on nominal variables. For instance, we considered the use of real predictor variables such as industrial production, employment and the building materials index. However, only a few SPINS have quarterly data going back to 1980: Fiji (only an industrial production index), PNG (only the employment index) and the Solomon Islands (only a production index). Other countries, like Tonga, only have data on the manufacturing index, but it is available on an infrequent basis and for a short span only. PNG's building survey data has not been updated in the last two decades, and Vanuatu does not have an adequate real measure of any GDP-related variable for the period required. Samoa was the only country that started compiling quarterly GDP but the series is too short for any robust time-series regression analysis. We explored various sources of data, including a respective country's National Statistical Office, Central Bank and Finance Department, all of which have websites. However, our main data sources are the International Financial Statistics (IFS) database, the World Economic Outlook (WEO) database and the United Nations Statistics Division (UNSD) National Accounts Aggregates database.

Based on the aforementioned reasons, we use related nominal predictor variables in connection with nominal GDP instead of real predictor variables in connection with real GDP. However, while it is desirable to have more than two predictor variables for the Chow-Lin procedure to generate GDP estimates, in the case of the SPINS even the availability of nominal variables has been sparse. To ascertain the suitability of GDP-related variables for the data disaggregation procedure, we estimate the basic regression equation below, for each country, with annual data:

$$
y_{t}=\beta+\beta_{1} X_{1 t}+\beta_{2} X_{2 t}+u_{t},
$$

where $y_{t}$ is the natural log of nominal GDP at time $t$ for all countries, $X_{1 t}$ is the natural $\log$ of money supply (M1 or M2) at time $t$, and $X_{2 t}$ is the natural log of exports or net-exports at time $t$. 
Before deciding on money supply $\left(X_{l t}\right)$ and exports or net-exports $\left(X_{2 t}\right)$ as predictor variables for the data disaggregation procedure, we carefully considered several other GDP-related variables. We investigated the availability of suitable nominal quarterly variables, including imports and exports, price indices, exchange rates and monetary aggregates. Other associated data on balance of payments and government finance data are mainly available only on an annual frequency. We specify all variables in natural logarithms except for net-exports that show negative values and are therefore modelled in levels along with all other variables in the regression. After several data diagnoses and GLS regressions, we chose exports and the money supply as predictor variables. ${ }^{4}$ In general, estimation of equation (7) for each country shows that money, exports and net-exports are suitable GDP-predictor variables.

\subsection{Tests for Unit Roots}

We first examine the statistical properties of the annual data through standard unit root tests. All the series are tested for unit roots based on a model with a constant and deterministic time trend in the test regression. The unit root tests ascertain the order of integration for nominal GDP and the GDP-related nominal series that we use (i.e., exports, money supply and net-exports). More specifically, our unit root tests show that nominal GDP is $I(1)$ for all the countries, using the Augmented Dickey-Fuller (ADF) test and Akaike's (1973) information criterion (AIC) to select the lag augmentations. Exports are $I(1)$ for all countries except for the Solomon Islands which shows $I(2)$. Therefore, we used the first difference for exports, which is I(1) and represents the growth rate of exports. Money, M1, is $I(1)$ for all countries, except for Vanuatu and Fiji for which it is $I(0)$. We use M2 and net-exports instead for Vanuatu because both are $I(1)$ and highly correlated with nominal GDP, unlike exports and M1. For Fiji, we use M2 (instead of M1) which is $I(1)$. The tests for real annual GDP show for all countries that $I(1)$ best describes the time series behaviour over the sample period. While the test results meet our expectations, we acknowledge that the small sample size may adversely affect the test power.

\footnotetext{
${ }^{4}$ We test for unit roots and cointegration and run appropriate regressions to ascertain the goodness of fit of the model $\left(\mathrm{R}^{2}\right)$ relating GDP with the chosen predictor variables. We also examine whether there is strong correlation among GDP and the predictor variables, and check for correct signs of coefficients of the variables to ensure that the relationship makes economic sense.
} 


\subsection{Tests for Cointegration}

Johansen (1988) and Johansen and Juselius (1990) propose two maximum-likelihood based tests for cointegration: a likelihood ratio trace-test and a maximum eigen-value ( $\lambda$-max) test. If each series follows a unit root process and GDP and the related series are cointegrated, we set $\mathrm{D}=\mathrm{I}$ in equation (5). Cointegration leads to super-consistent parameter estimates of least squares regressions (Sims et al., 1990). We next obtain the residuals from $\hat{u}_{a}=y_{a}-X_{a} \hat{\beta}_{a}$ and regress $\hat{u}_{a, t}=\rho_{a} \hat{u}_{a, t-1}+e_{a, t}$ to obtain the estimated value of $\rho_{a}$, denoted $\hat{\rho}_{a}$, which is used to calculate $\hat{\rho}_{q}$ from equation (6) in order to be plugged into the $H$ matrix.

Cointegration test results often depend critically on the number of lagged differences included in the regression equation. The reason for the augmentation of the lagged differences is to ensure that the errors are white noise. We use AIC in order to determine the appropriate lag length of the vector autoregressive (VAR) model for the cointegration tests. Considering the short span of time series data available (1980 to 2006), the maximum lag for the lag selection is set at 4 . Once the optimal lag length was established, cointegration among the series was tested based on the Johansen cointegration tests. Cointegration among the variables means that annual GDP can be represented as a vector error-correction model. We allow for deterministic time trends in the underlying time series but not in the cointegrating vectors. The cointegration tests show evidence of long-run cointegrating relationships among nominal GDP and the corresponding predictor variables in all countries except for Fiji. ${ }^{5}$ The result for Fiji is inconsistent with what one expects. A predictor variable should move together with the variable it is supposed to be related with and therefore the two should be cointegrated. ${ }^{6}$

In cases where a cointegrating relationship is not evident, we follow Fernandez (1981) and Litterman's (1983) suggestions and estimate the residuals based on the first-

\footnotetext{
${ }^{5}$ The trace and the maximum eigen-value tests lead to the same results except for Tonga where cointegration is found for the trace test only. We used critical values based on MacKinnon et al. (1999).

${ }^{6}$ Abeysinghe and Rajaguru (2004) found much less evidence for cointegration in their data and hence used growth rates instead.
} 
differenced series, i.e., $\hat{\varepsilon}_{a, t}=\Delta y_{a}-\Delta X_{a} \hat{\beta}_{a}$, and then regress $\hat{\varepsilon}_{a, t}$ on its lagged value, i.e., $\hat{\varepsilon}_{a, t}=\rho_{a} \hat{\varepsilon}_{a, t-1}+v_{t}$, to obtain $\hat{\rho}_{a}$. Since the GDP series we use are in natural logs, the first-differenced series are the growth rates of GDP.

\subsection{Deriving GDP estimates for the SPINS}

The Johansen cointegration tests support cointegration among the variables of interest for the SPINS. We therefore set $\mathrm{D}=\mathrm{I}$ in equation (5) and estimated the quarterly nominal GDP series from the corresponding annual series and the quarterly series of the predictors according to equation (6). For PNG, we find that $\hat{\rho}_{a}=0.4285$ and $\hat{\rho}_{q}$ $=0.5841$; for Samoa we find $\hat{\rho}_{a}=0.3587$ and $\hat{\rho}_{q}=0.4712$; for the Solomon Islands we find $\hat{\rho}_{a}=0.6775$ and $\hat{\rho}_{q}=0.8229$; for Tonga, we find $\hat{\rho}_{a}=0.6674$ and $\hat{\rho}_{q}=$ 0.8157; and for Vanuatu, we find $\hat{\rho}_{a}=0.5277$ and $\hat{\rho}_{q}=0.6991$.

Since no cointegration among the variables of interest is evident for Fiji, the quarterly nominal GDP is estimated from the first-differenced series (annual nominal GDP and quarterly predictor variables specified all as growth rates) following equation (5) . We tested for no correlation at lag 1 using the Breusch-Godfrey serial correlation LM-test and the test statistic was insignificant, indicating no autocorrelation in the regression residuals so that we set $\rho_{q}=0$ for Fiji. The resulting quarterly nominal GDP series for the SPINS are presented in Table 1.

\section{$4 \quad$ Implicit GDP Deflators}

After deriving quarterly nominal GDP estimates, the series are adjusted to arrive at quarterly real GDP estimates, using the derived GDP deflator. Since the GDP deflators were available only annually from the IFS, WEO and UNSD databases, we also had to derive quarterly estimates for this variable using the modified Chow-Lin method. Identifying predictor variables also meant finding co-movement among related variables. After numerous checks for relevant predictor variables, the consumer price index (CPI) and money supply, M1, were chosen as predictors for all the countries, except for Fiji, where M2 was selected, and Vanuatu where the 
exchange rate was used in place of money. ${ }^{7}$ Our unit root tests based on the ADF and AIC, and allowing for a constant and deterministic time trend in the series, show that the GDP deflators for all countries are I(1). The CPIs for Fiji and Samoa are I(1) while the others are $I(2)$. The natural logarithms of money, M1, for all countries are $I(1)$, except for Fiji and Vanuatu. For Fiji, we used instead M2's growth rate that is $I(1)$. For Vanuatu, we used instead of M1 the exchange rate that is $I(1)$. The predictor variables that were $I(2)$ were transformed to $I(1)$ by first-differencing ${ }^{8}$ for the Johansen cointegration test (using up to 4 lags), and also for the modified Chow-Lin procedure. All annual deflator and predictor variables were cointegrated, allowing for deterministic time trends in the underlying time series but not in the cointegrating vectors, when testing for cointegration. Similarly to estimating quarterly nominal GDP, we set $\mathrm{D}=\mathrm{I}$ in equation (5) and estimated the quarterly deflator series according to equation (6). In determining the annual and quarterly correlation coefficient at lag 1, we find for Fiji, $\hat{\rho}_{a}=0.4905$ and $\hat{\rho}_{q}=0.6603$; for PNG, $\hat{\rho}_{a}=0.8185$ and $\hat{\rho}_{q}=$ 0.9105; for Samoa, $\hat{\rho}_{a}=0.7363$ and $\hat{\rho}_{q}=0.8619$; for the Solomon Islands, $\hat{\rho}_{a}=0.9124$ and $\hat{\rho}_{q}=0.9593$; for Tonga, $\hat{\rho}_{a}=0.7289$ and $\hat{\rho}_{q}=0.8572$; and for Vanuatu, we find $\hat{\rho}_{a}=0.8435$ and $\hat{\rho}_{q}=0.9241$.

\section{$5 \quad$ Quality of the Disaggregated GDP series}

After deriving quarterly nominal GDP estimates, the series are adjusted to arrive at quarterly real GDP estimates, using the derived GDP price deflator. In order to ensure that the quarterly real GDP estimates we have derived for the SPINS are consistent and reliable, we tested for unit roots, which generally shows that our disaggregated real GDP estimates for all countries are $I(1) .^{9}$ This is consistent with our results for annual data. We also computed annual real GDP series from the quarterly real series we have just derived with the modified Chow-Lin procedure and compared these with published annual real GDP from the IFS and WEO in order to ensure accuracy and consistency of our results. Where the published annual real GDP data were not of the required base year (year 2000), the series were re-based.

\footnotetext{
${ }^{7}$ Including exchange rates resulted in cointegration among the variables for Vanuatu, whereas netexports did not.

${ }^{8}$ In the case of the CPI, the logs of first differences (inflation rates) were used.

${ }^{9}$ According to Marcellino (1999), disaggregation should not affect the $I(1)$ property of the series-
} 
We show in Figure 1 how our quarterly GDP estimates (seasonally adjusted) compare with the published annual series from IFS and WEO. As can be seen, although the quarterly estimates appear more volatile than the annual series, they nonetheless still generally follow the annual trend, i.e., they show consistent behaviour with the annual GDP trend. Note too that the volatility of the quarterly estimates of the SPINS can be characterised by unforeseen events like the frequent occurrence of natural disasters that caused severe damage to the economies of the SPINS. For example, Samoa was affected by two major cyclone disasters in 1990, as well as Vanuatu in 2001. Furthermore, external and internal shocks relating to world commodity price volatility and political instability have also affected the economies of some of the SPINS. Moreover, it is worthwhile to note that our constructed quarterly series for Samoa follows a trend very similar to the quarterly series published by Samoa's Ministry of Finance from 1994 onwards. ${ }^{10}$ When growth rates (year-on-year and quarter-toquarter) are compared, there appear to be some minor differences (positive and negative growth rates) which can be attributed to differences in data compilation. Further, we note that the relative size of volatility of our quarterly estimates affects the growth rates.

\section{Summary}

This paper addresses the problem of lack of time-series data for many of the South Pacific Island Nations by applying the basic methodology of Chow and Lin (1971) for deriving quarterly GDP estimates from annual data. We take particular care in first identifying the extent and nature of the relationships among the annual nominal and real GDP variable on the one hand and associated annual predictor variables on the other hand. In relation to this, the choice of the appropriate set of variables to use for the decomposition procedure involved testing for cointegrating relationships among the relevant variables in order to determine co-movement among these variables. We validate the consistency and reliability of our quarterly GDP estimates by carefully examining the behaviour of the estimated quarterly series in relation to the published annual series.

\footnotetext{
${ }^{10}$ Unlike for the other countries, Samoa's quarterly GDP series was provided by the Ministry of Finance from 1994:Q1 to 2006:Q4, so that we could compare our estimates to those produced by the Ministry.
} 


\section{References}

Abeysinghe, T. and Rajaguru, G. (2004). "Quarterly Real GDP Estimates for China and ASEAN4 with a Forecast Evaluation”. Journal of Forecasting, 23, 432-447.

Akaike, H. (1973). "Information Theory and an Extension of the Maximum Likelihood Principle", in 2nd International Symposium on Information Theory, Petrov, B.N. and Csaki, F. (eds), Akademiai Kiado, 267-281.

Armstrong, H., de Kervenoael, R.J., Li, X. and Read, R. (1998). “A Comparison of the Economic Performance of Different Micro-states, and Between Micro-states and Larger Countries". World Development, 26, 639-656.

Armstrong, H. and Read, R. (2002). "The Phantom of Liberty?: Economic Growth and the Vulnerability of Small States". Journal of International Development, 14, 435-458.

Briguglio, L. (1995). "Small Island Developing States and Their Economic Vulnerabilities". World Development, 23, 1615-1632.

Chow, G. C. and Lin, A. (1971). "Best Linear Unbiased Interpolation, Distribution, and Extrapolation of Time Series by Related Series". Review of Economics and Statistics, 53, 372-375

Easterly, W. and Kraay, A. (2000). "Small States, Small Problems? Income, Growth and Volatility in Small States". World Development, 28, 2013-2027.

Fernandez, R.B. (1981). "A Methodological Note on the Estimation of Time Series. Review of Economics and Statistics", 63, 471-476.

FEMM. (2000). Forum Economic Ministers Meeting, 25-16 July, 2000. Record of Meeting Decisions. Alofi, Niue.

Hall, V. and McDermott, J. (2007). “A Quarterly Post-World War II Real GDP Series for New Zealand”. Motu Working Paper 07-13, Motu Economic and Public Policy Research.

Haug, A. A. (2002). "Temporal Aggregation and the Power of Cointegration Tests: A Monte Carlo Study." Oxford Bulletin of Economics and Statistics, 64, 399-412

International Monetary Fund (2007). International Financial Statistics: Available at: http://ifs.apdi.net/imf/imfbrowser.aspx?branch=ROOT

International Monetary Fund (2006). World Economic Outlook Database: Available at: http://www.imf.org/external/pubs/ft/weo/2006/02/data/index.aspx

Johansen, J. (1988). "Statistical analysis of cointegration vectors", Journal of Economic Dynamics and Control, 12, 231-254. 
Johansen, S and K. Juselius (1990).Maximum Likelihood Estimation and Inference on Cointegration - With Applications to the Demand for Money, Oxford Bulletin of Economics and Statistics, 52, 169-210.

Johansen, S. (1992). "Determination of Cointegration Rank in the Presence of a Linear Trend", Oxford Bulletin of Economics and Statistics, 54, 383-397.

Johansen, J. (1995). A Statistical Analysis of Cointegration for I(2) Variables. Econometric Theory, 11, 25-59

Litterman R.B. (1983). A Random Walk, Markov model for the Distribution of Time Series. Journal of Business and Economic Statistics, 1, 169-173.

MacKinnon, J. G., Haug, A. A. and Michelis, L. (1999). "Numerical Distribution Functions of Likelihood Ratio Tests for Cointegration". Journal of Applied Econometrics, 14, 563-577.

Marcellino, M. (1999). "Some Consequences of Temporal Aggregation in Empirical Analysis". Journal of Business and Economic Statistics, 17,129-136.

Moauro, F. and Savio, G. (2005). "Temporal disaggregation using multivariate structural time series models". Econometrics Journal, 8, 214-234.

Ng, S. and Perron, P. (2001). "Lag Length Selection and the Construction of Unit Root Tests with Good Size and Power", Econometrica, 69, 1519-1554.

Schwarz, G. (1978). "Estimating the Dimension of a Model”, The Annals of Statistics, 6, 461-464.

Secretariat of the Pacific Community. (2003). Thirteenth Regional Meeting of Heads of Statistics, Regional Meeting of Heads of Statistics 13 List of Meeting Papers, Noumea. SPC / STATS 13 Working Paper 6. Available at: http://www.spc.int/statsen/English/News_and_Events/Stats13/REPORT.htm

Secretariat of the Pacific Community. (2005). Regional Meeting of Heads of Planning and Heads of Statistics, Planners and Statisticians Meeting, Noumea. Available at: http://www.spc.int/statsen/English/News_and_Events/RMHPS2005/RMHPS2005.htm

Secretariat of the Pacific Community. (2007). Regional Meeting of Heads of Planning and Heads of Statistics, Noumea. Available at:

$\mathrm{http}: / / \mathrm{www} . \mathrm{spc} . \mathrm{int} / \mathrm{sdp} / \mathrm{index}$.php?option=com_content\&task=view\&id=25\&Itemid=1

Sims, C.A., Stock, J.H. and Watson, M.W. (1990). "Inference in Linear Time Series Models with Some Unit Roots". Econometrica, 58, 161-82.

United Nations Statistics Division (2007). National Accounts Main Aggregates Database. Available at: http://unstats.un.org/unsd/snaama/dnllist.asp 
Table 1

Disaggregated Quarterly Real and Nominal GDP for the SPINs

\begin{tabular}{|c|c|c|c|c|c|c|c|c|c|c|c|c|}
\hline \multirow{2}{*}{$\begin{array}{l}\text { Quarter/ } \\
\text { Year }\end{array}$} & \multicolumn{6}{|c|}{ Real GDP (base year 2000) in millions of local currency } & \multicolumn{6}{|c|}{ Nominal GDP in millions of local currency } \\
\hline & FIJI & PNG & SAMOA & $\begin{array}{l}\text { SOLOMON } \\
\text { ISLANDS }\end{array}$ & TONGA & VANUATU & FIJI & PNG & SAMOA & $\begin{array}{l}\text { SOLOMON } \\
\text { ISLANDS }\end{array}$ & TONGA & VANUATU \\
\hline Q1 1980 & 2,047 & 2,132 & 532 & 821 & 86 & 17,178 & 881 & 796 & 112 & 111 & 31 & 7,090 \\
\hline Q2 1980 & 1,976 & 8,255 & 648 & 819 & 144 & 18,569 & 905 & 2,846 & 145 & 107 & 66 & 7,182 \\
\hline Q3 1980 & 2,005 & 5,788 & 743 & 1,202 & 136 & 20,406 & 937 & 1,931 & 166 & 173 & 56 & 7,609 \\
\hline Q4 1980 & 2,549 & 5,911 & 522 & 1,269 & 138 & 19,351 & 1,187 & 1,941 & 144 & 191 & 53 & 7,638 \\
\hline Q1 1981 & 2,295 & 5,972 & 590 & 1,122 & 126 & 21,348 & 1,044 & 1,973 & 160 & 171 & 46 & 8,605 \\
\hline Q2 1981 & 2,340 & 5,684 & 551 & 1,100 & 178 & 19,442 & 1,047 & 1,899 & 151 & 173 & 79 & 9,018 \\
\hline Q3 1981 & 2,303 & 4,925 & 602 & 1,027 & 129 & 19,082 & 1,044 & 1,646 & 158 & 162 & 44 & 8,861 \\
\hline Q4 1981 & 2,347 & 5,350 & 482 & 895 & 119 & 18,984 & 1,086 & 1,836 & 132 & 147 & 35 & 9,161 \\
\hline Q1 1982 & 2,303 & 4,101 & 449 & 1,027 & 205 & 18,923 & 1,100 & 1,398 & 117 & 177 & 89 & 9,422 \\
\hline Q2 1982 & 2,279 & 5,030 & 560 & 999 & 151 & 19,541 & 1,111 & 1,727 & 134 & 174 & 51 & 9,286 \\
\hline Q3 1982 & 2,261 & 7,304 & 544 & 954 & 162 & 20,124 & 1,123 & 2,493 & 129 & 171 & 58 & 9,755 \\
\hline Q4 1982 & 2,215 & 5,512 & 652 & 1,059 & 163 & 21,547 & 1,119 & 1,977 & 140 & 201 & 60 & 10,827 \\
\hline Q1 1983 & 2,253 & 5,939 & 642 & 974 & 177 & 20,301 & 1,152 & 2,171 & 150 & 181 & 68 & 9,671 \\
\hline Q2 1983 & 2,231 & 5,862 & 547 & 1,071 & 144 & 21,646 & 1,152 & 2,205 & 144 & 202 & 48 & 10,638 \\
\hline Q3 1983 & 2,229 & 5,567 & 470 & 1,147 & 197 & 19,904 & 1,159 & 2,134 & 143 & 225 & 84 & 10,377 \\
\hline Q4 1983 & 2,124 & 5,487 & 556 & 1,004 & 207 & 20,685 & 1,111 & 2,118 & 176 & 198 & 94 & 10,903 \\
\hline Q1 1984 & 2,124 & 5,827 & 577 & 1,159 & 177 & 20,060 & 1,121 & 2,224 & 178 & 236 & 70 & 11,333 \\
\hline Q2 1984 & 2,321 & 5,366 & 490 & 1,060 & 178 & 22,456 & 1,235 & 2,017 & 159 & 221 & 70 & 12,487 \\
\hline Q3 1984 & 2,370 & 5,543 & 573 & 957 & 188 & 23,809 & 1,261 & 2,089 & 188 & 210 & 78 & 13,963 \\
\hline Q4 1984 & 2,705 & 5,747 & 585 & 1,050 & 191 & 21,678 & 1,460 & 2,169 & 196 & 229 & 76 & 12,735 \\
\hline Q1 1985 & 2,311 & 6,511 & 562 & 1,014 & 186 & 22,726 & 1,295 & 2,426 & 191 & 228 & 72 & 13,175 \\
\hline Q2 1985 & 2,394 & 5,481 & 537 & 1,058 & 201 & 21,529 & 1,371 & 2,064 & 179 & 249 & 81 & 13,316 \\
\hline Q3 1985 & 2,304 & 5,011 & 633 & 929 & 203 & 23,088 & 1,334 & 1,901 & 200 & 214 & 81 & 13,237 \\
\hline Q4 1985 & 2,175 & 6,246 & 590 & 1,077 & 199 & 21,848 & 1,272 & 2,392 & 193 & 254 & 85 & 11,653 \\
\hline Q1 1986 & 2,251 & 6,369 & 630 & 1,106 & 199 & 24,277 & 1,323 & 2,435 & 209 & 261 & 92 & 13,494 \\
\hline Q2 1986 & 2,327 & 6,498 & 677 & 965 & 199 & 20,929 & 1,386 & 2,485 & 222 & 236 & 97 & 11,678 \\
\hline Q3 1986 & 2,496 & 7,119 & 590 & 1,037 & 208 & 21,677 & 1,500 & 2,670 & 195 & 254 & 107 & 11,728 \\
\hline Q4 1986 & 2,642 & 4,517 & 561 & 984 & 201 & 20,704 & 1,608 & 1,683 & 181 & 247 & 104 & 13,020 \\
\hline
\end{tabular}


Table 1 continued

\begin{tabular}{|c|c|c|c|c|c|c|c|c|c|c|c|c|}
\hline \multirow{2}{*}{$\begin{array}{l}\text { Quarter/ } \\
\text { Year }\end{array}$} & \multicolumn{6}{|c|}{ Real GDP (base year 2000) in millions of local currency } & \multicolumn{6}{|c|}{ Nominal GDP in millions of local currency } \\
\hline & FIJI & PNG & SAMOA & $\begin{array}{c}\text { SOLOMON } \\
\text { ISLANDS }\end{array}$ & TONGA & VANUATU & FIJI & PNG & SAMOA & $\begin{array}{c}\text { SOLOMON } \\
\text { ISLANDS }\end{array}$ & TONGA & VANUATU \\
\hline Q1 1987 & 2,585 & 6,357 & 579 & 967 & 220 & 22,013 & 1,613 & 2,234 & 191 & 252 & 122 & 13,417 \\
\hline Q2 1987 & 2,416 & 4,241 & 619 & 1,102 & 212 & 22,315 & 1,518 & 1,552 & 203 & 290 & 113 & 13,648 \\
\hline Q3 1987 & 2,167 & 6,693 & 630 & 1,218 & 198 & 20,447 & 1,405 & 2,565 & 212 & 333 & 107 & 13,435 \\
\hline Q4 1987 & 2,019 & 7,646 & 617 & 1,110 & 199 & 23,098 & 1,340 & 3,139 & 234 & 323 & 116 & 14,410 \\
\hline Q1 1988 & 2,265 & 7,683 & 637 & 1,033 & 197 & 21,454 & 1,542 & 3,510 & 250 & 327 & 126 & 14,911 \\
\hline Q2 1988 & 2,285 & 6,842 & 512 & 1,163 & 224 & 21,909 & 1,553 & 3,300 & 221 & 376 & 158 & 14,836 \\
\hline Q3 1988 & 2,306 & 5,185 & 606 & 1,068 & 188 & 21,340 & 1,560 & 2,590 & 245 & 336 & 135 & 15,442 \\
\hline Q4 1988 & 2,498 & 6,454 & 666 & 1,204 & 200 & 23,565 & 1,674 & 3,290 & 263 & 385 & 141 & 16,339 \\
\hline Q1 1989 & 2,563 & 6,780 & 605 & 1,153 & 222 & 21,263 & 1,669 & 3,269 & 242 & 371 & 160 & 15,187 \\
\hline Q2 1989 & 2,564 & 6,778 & 768 & 1,166 & 201 & 21,975 & 1,660 & 3,188 & 286 & 367 & 140 & 15,871 \\
\hline Q3 1989 & 2,746 & 6,610 & 569 & 1,198 & 199 & 22,659 & 1,781 & 3,117 & 225 & 383 & 143 & 17,335 \\
\hline Q4 1989 & 2,857 & 5,316 & 583 & 1,151 & 192 & 25,841 & 1,872 & 2,527 & 239 & 417 & 138 & 18,765 \\
\hline Q1 1990 & 2,648 & 5,557 & 560 & 1,124 & 179 & 25,384 & 1,808 & 2,681 & 234 & 461 & 130 & 18,508 \\
\hline Q2 1990 & 2,746 & 5,075 & 578 & 1,164 & 197 & 25,610 & 1,925 & 2,511 & 257 & 508 & 153 & 18,718 \\
\hline Q3 1990 & 2,983 & 5,965 & 594 & 1,255 & 196 & 26,540 & 2,105 & 2,962 & 256 & 565 & 158 & 18,409 \\
\hline Q4 1990 & 2,830 & 8,493 & 669 & 1,213 & 213 & 24,894 & 2,047 & 4,274 & 285 & 571 & 182 & 17,918 \\
\hline Q1 1991 & 2,910 & 3,426 & 669 & 1,314 & 205 & 26,118 & 2,154 & 1,801 & 295 & 616 & 179 & 18,989 \\
\hline Q2 1991 & 2,808 & 11,520 & 632 & 1,272 & 194 & 28,813 & 2,085 & 5,993 & 275 & 594 & 172 & 22,122 \\
\hline Q3 1991 & 2,599 & 7,335 & 547 & 1,246 & 201 & 26,006 & 1,962 & 3,889 & 256 & 587 & 184 & 21,126 \\
\hline Q4 1991 & 2,625 & 5,451 & 515 & 1,238 & 237 & 26,016 & 1,988 & 2,939 & 248 & 602 & 226 & 21,332 \\
\hline Q1 1992 & 2,580 & 5,924 & 640 & 1,311 & 184 & 27,736 & 1,954 & 3,257 & 317 & 659 & 164 & 23,086 \\
\hline Q2 1992 & 3,067 & 6,719 & 490 & 1,427 & 228 & 24,492 & 2,356 & 3,674 & 251 & 745 & 216 & 20,500 \\
\hline Q3 1992 & 2,944 & 7,454 & 628 & 1,465 & 242 & 28,463 & 2,379 & 4,075 & 306 & 803 & 233 & 23,179 \\
\hline Q4 1992 & 3,072 & 11,488 & 598 & 1,476 & 197 & 25,625 & 2,483 & 6,125 & 289 & 849 & 180 & 21,854 \\
\hline Q1 1993 & 2,955 & 8,662 & 588 & 1,409 & 232 & 27,629 & 2,414 & 4,594 & 270 & 812 & 218 & 24,162 \\
\hline Q2 1993 & 2,938 & 10,635 & 675 & 1,640 & 213 & 28,004 & 2,431 & 5,613 & 305 & 983 & 198 & 24,302 \\
\hline Q3 1993 & 3,128 & 10,046 & 621 & 1,447 & 203 & 27,708 & 2,585 & 5,305 & 307 & 910 & 179 & 23,961 \\
\hline Q4 1993 & 3,179 & 7,167 & 558 & 1,426 & 239 & 27,646 & 2,650 & 3,836 & 331 & 897 & 213 & 25,374 \\
\hline
\end{tabular}


Table 1 continued

\begin{tabular}{|c|c|c|c|c|c|c|c|c|c|c|c|c|}
\hline \multirow{2}{*}{$\begin{array}{l}\text { Quarter/ } \\
\text { Year }\end{array}$} & \multicolumn{6}{|c|}{ Real GDP (base year 2000) in millions of local currency } & \multicolumn{6}{|c|}{ Nominal GDP in millions of local currency } \\
\hline & FIJI & PNG & SAMOA & $\begin{array}{c}\text { SOLOMON } \\
\text { ISLANDS }\end{array}$ & TONGA & VANUATU & FIJI & PNG & SAMOA & $\begin{array}{c}\text { SOLOMON } \\
\text { ISLANDS }\end{array}$ & TONGA & VANUATU \\
\hline Q1 1994 & 3,158 & 9,401 & 597 & 1,568 & 204 & 26,115 & 2,620 & 5,061 & 459 & 984 & 174 & 24,116 \\
\hline Q2 1994 & 3,346 & 8,068 & 574 & 1,513 & 215 & 28,436 & 2,780 & 4,509 & 497 & 956 & 179 & 26,178 \\
\hline Q3 1994 & 3,201 & 10,345 & 588 & 1,575 & 256 & 27,777 & 2,646 & 5,911 & 514 & 1,068 & 219 & 25,284 \\
\hline Q4 1994 & 3,179 & 11,262 & 614 & 1,812 & 252 & 30,083 & 2,662 & 6,824 & 519 & 1,202 & 212 & 26,843 \\
\hline Q1 1995 & 3,331 & 9,256 & 563 & 1,821 & 245 & 29,670 & 2,779 & 5,847 & 443 & 1,203 & 200 & 25,584 \\
\hline Q2 1995 & 3,345 & 8,438 & 572 & 1,903 & 267 & 27,426 & 2,794 & 5,472 & 438 & 1,293 & 223 & 24,404 \\
\hline Q3 1995 & 3,333 & 4,860 & 676 & 1,537 & 240 & 32,646 & 2,792 & 3,393 & 524 & 1,103 & 200 & 27,948 \\
\hline Q4 1995 & 3,351 & 16,407 & 707 & 1,739 & 211 & 31,016 & 2,847 & 10,842 & 559 & 1,259 & 174 & 27,011 \\
\hline Q1 1996 & 3,428 & 12,085 & 713 & 1,964 & 250 & 29,431 & 2,951 & 8,020 & 554 & 1,483 & 224 & 26,298 \\
\hline Q2 1996 & 3,357 & 11,212 & 677 & 1,733 & 251 & 31,584 & 2,922 & 7,458 & 544 & 1,341 & 234 & 27,938 \\
\hline Q3 1996 & 3,443 & 8,833 & 689 & 1,704 & 221 & 31,092 & 3,020 & 6,025 & 565 & 1,347 & 203 & 27,149 \\
\hline Q4 1996 & 3,391 & 7,852 & 647 & 1,721 & 233 & 31,589 & 2,964 & 5,535 & 557 & 1,372 & 216 & 28,391 \\
\hline Q1 1997 & 3,405 & 9,061 & 685 & 1,706 & 258 & 34,674 & 3,019 & 6,777 & 607 & 1,379 & 245 & 31,135 \\
\hline Q2 1997 & 3,375 & 11,617 & 680 & 1,704 & 221 & 32,034 & 3,010 & 8,819 & 608 & 1,423 & 201 & 29,365 \\
\hline Q3 1997 & 3,524 & 9,376 & 602 & 1,823 & 218 & 31,921 & 3,123 & 7,102 & 568 & 1,503 & 196 & 29,217 \\
\hline Q4 1997 & 3,481 & 7,166 & 773 & 1,779 & 230 & 31,122 & 3,094 & 5,430 & 712 & 1,492 & 210 & 29,052 \\
\hline Q1 1998 & 3,454 & 8,735 & 729 & 1,669 & 230 & 34,698 & 3,133 & 6,772 & 684 & 1,437 & 210 & 32,872 \\
\hline Q2 1998 & 3,537 & 10,112 & 710 & 1,737 & 233 & 28,361 & 3,304 & 7,898 & 680 & 1,534 & 216 & 27,785 \\
\hline Q3 1998 & 3,409 & 10,462 & 679 & 1,978 & 260 & 36,221 & 3,300 & 8,386 & 634 & 1,720 & 250 & 34,338 \\
\hline Q4 1998 & 3,377 & 10,152 & 703 & 1,744 & 242 & 36,559 & 3,388 & 8,373 & 656 & 1,543 & 231 & 34,968 \\
\hline Q1 1999 & 3,337 & 7,699 & 643 & 1,570 & 234 & 33,988 & 3,401 & 6,289 & 623 & 1,387 & 224 & 33,347 \\
\hline Q2 1999 & 3,442 & 7,234 & 722 & 1,977 & 248 & 31,815 & 3,539 & 6,305 & 694 & 1,778 & 243 & 31,941 \\
\hline Q3 1999 & 3,491 & 10,872 & 721 & 1,811 & 255 & 32,724 & 3,592 & 10,017 & 722 & 1,622 & 254 & 32,643 \\
\hline Q4 1999 & 4,039 & 14,753 & 752 & 1,741 & 251 & 32,765 & 4,143 & 13,649 & 722 & 1,629 & 251 & 31,712 \\
\hline Q1 2000 & 3,945 & 11,739 & 743 & 1,824 & 249 & 33,435 & 3,937 & 11,393 & 724 & 1,736 & 249 & 32,665 \\
\hline Q2 2000 & 3,552 & 10,827 & 736 & 1,512 & 255 & 33,259 & 3,547 & 10,789 & 720 & 1,498 & 251 & 33,204 \\
\hline Q3 2000 & 3,342 & 8,495 & 766 & 1,396 & 283 & 32,629 & 3,347 & 8,519 & 773 & 1,429 & 287 & 32,746 \\
\hline Q4 2000 & 3,275 & 7,657 & 788 & 1,381 & 254 & 35,541 & 3,278 & 7,885 & 816 & 1,429 & 256 & 36,229 \\
\hline
\end{tabular}


Table 1 continued

\begin{tabular}{|c|c|c|c|c|c|c|c|c|c|c|c|c|}
\hline \multirow{2}{*}{$\begin{array}{l}\text { Quarter/ } \\
\text { Year }\end{array}$} & \multicolumn{6}{|c|}{ Real GDP (base year 2000) in millions of local currency } & \multicolumn{6}{|c|}{ Nominal GDP in millions of local currency } \\
\hline & FIJI & PNG & SAMOA & $\begin{array}{l}\text { SOLOMON } \\
\text { ISLANDS }\end{array}$ & TONGA & VANUATU & FIJI & PNG & SAMOA & $\begin{array}{l}\text { SOLOMON } \\
\text { ISLANDS }\end{array}$ & TONGA & VANUATU \\
\hline Q1 2001 & 3,455 & 11,070 & 872 & 1,314 & 269 & 36,099 & 3,522 & 11,546 & 888 & 1,362 & 273 & 36,893 \\
\hline Q2 2001 & 3,604 & 9,242 & 841 & 1,396 & 261 & 34,753 & 3,688 & 9,784 & 877 & 1,451 & 268 & 36,159 \\
\hline Q3 2001 & 3,747 & 9,326 & 802 & 1,395 & 256 & 26,802 & 3,857 & 10,050 & 826 & 1,449 & 265 & 28,365 \\
\hline Q4 2001 & 3,847 & 9,103 & 734 & 1,434 & 276 & 33,544 & 4,022 & 9,983 & 771 & 1,515 & 297 & 34,981 \\
\hline Q1 2002 & 3,794 & 4,848 & 730 & 1,391 & 285 & 30,947 & 3,943 & 5,594 & 782 & 1,492 & 316 & 33,000 \\
\hline Q2 2002 & 3,926 & 12,355 & 924 & 1,366 & 259 & 31,125 & 4,120 & 14,633 & 997 & 1,502 & 289 & 31,478 \\
\hline Q3 2002 & 3,789 & 11,462 & 804 & 1,392 & 238 & 29,401 & 4,007 & 13,992 & 874 & 1,610 & 268 & 31,061 \\
\hline Q4 2002 & 3,543 & 11,339 & 798 & 1,299 & 308 & 30,133 & 3,774 & 14,094 & 881 & 1,532 & 370 & 32,384 \\
\hline Q1 2003 & 4,088 & 11,503 & 837 & 1,456 & 254 & 28,298 & 4,441 & 14,724 & 913 & 1,739 & 302 & 30,679 \\
\hline Q2 2003 & 3,550 & 7,998 & 748 & 1,413 & 290 & 32,235 & 3,926 & 10,197 & 838 & 1,684 & 357 & 34,887 \\
\hline Q3 2003 & 3,737 & 9,927 & 929 & 1,369 & 286 & 33,105 & 4,138 & 12,531 & 1,061 & 1,639 & 362 & 36,354 \\
\hline Q4 2003 & 4,007 & 9,628 & 847 & 1,551 & 291 & 32,003 & 4,445 & 12,021 & 964 & 1,874 & 370 & 35,052 \\
\hline Q1 2004 & 3,509 & 10,765 & 877 & 1,405 & 261 & 34,068 & 3,875 & 13,126 & 1,037 & 1,773 & 330 & 36,966 \\
\hline Q2 2004 & 4,100 & 8,869 & 851 & 1,664 & 301 & 32,310 & 4,611 & 10,830 & 1,014 & 2,084 & 391 & 36,309 \\
\hline Q3 2004 & 4,091 & 10,375 & 890 & 1,828 & 300 & 33,227 & 4,669 & 12,803 & 1,075 & 2,332 & 395 & 37,144 \\
\hline Q4 2004 & 4,261 & 10,467 & 878 & 1,372 & 276 & 32,841 & 4,957 & 13,505 & 1,057 & 1,757 & 368 & 37,138 \\
\hline Q1 2005 & 3,998 & 10,508 & 891 & 1,604 & 327 & 35,498 & 4,735 & 14,263 & 1,075 & 2,134 & 456 & 39,851 \\
\hline Q2 2005 & 3,942 & 12,891 & 943 & 1,644 & 291 & 32,742 & 4,767 & 18,378 & 1,146 & 2,207 & 411 & 37,012 \\
\hline Q3 2005 & 3,989 & 5,711 & 867 & 1,685 & 270 & 37,849 & 4,874 & 8,551 & 1,082 & 2,352 & 384 & 42,792 \\
\hline Q4 2005 & 3,721 & 13,367 & 973 & 1,639 & 282 & 35,329 & 4,555 & 20,676 & 1,207 & 2,272 & 419 & 41,275 \\
\hline Q1 2006 & 4,105 & 9,564 & 907 & 1,614 & 260 & 34,889 & 4,937 & 14,957 & 1,127 & 2,308 & 394 & 41,431 \\
\hline Q2 2006 & 4,273 & 12,676 & 937 & 1,491 & 230 & 36,372 & 5,104 & 20,240 & 1,189 & 2,150 & 344 & 42,977 \\
\hline Q3 2006 & 4,108 & 10,981 & 965 & 1,625 & 324 & 37,405 & 4,959 & 17,579 & 1,214 & 2,383 & 505 & 42,411 \\
\hline Q4 2006 & 4,255 & 10,585 & 1,004 & 2,108 & 369 & 40,824 & 5,170 & 16,571 & 1,291 & 3,114 & 569 & 45,788 \\
\hline
\end{tabular}




\section{Figure 1}

Comparison of Published Annual logs of Real GDP (Actual) with Estimated Quarterly logs of Real GDP (Disaggregated Estimate)
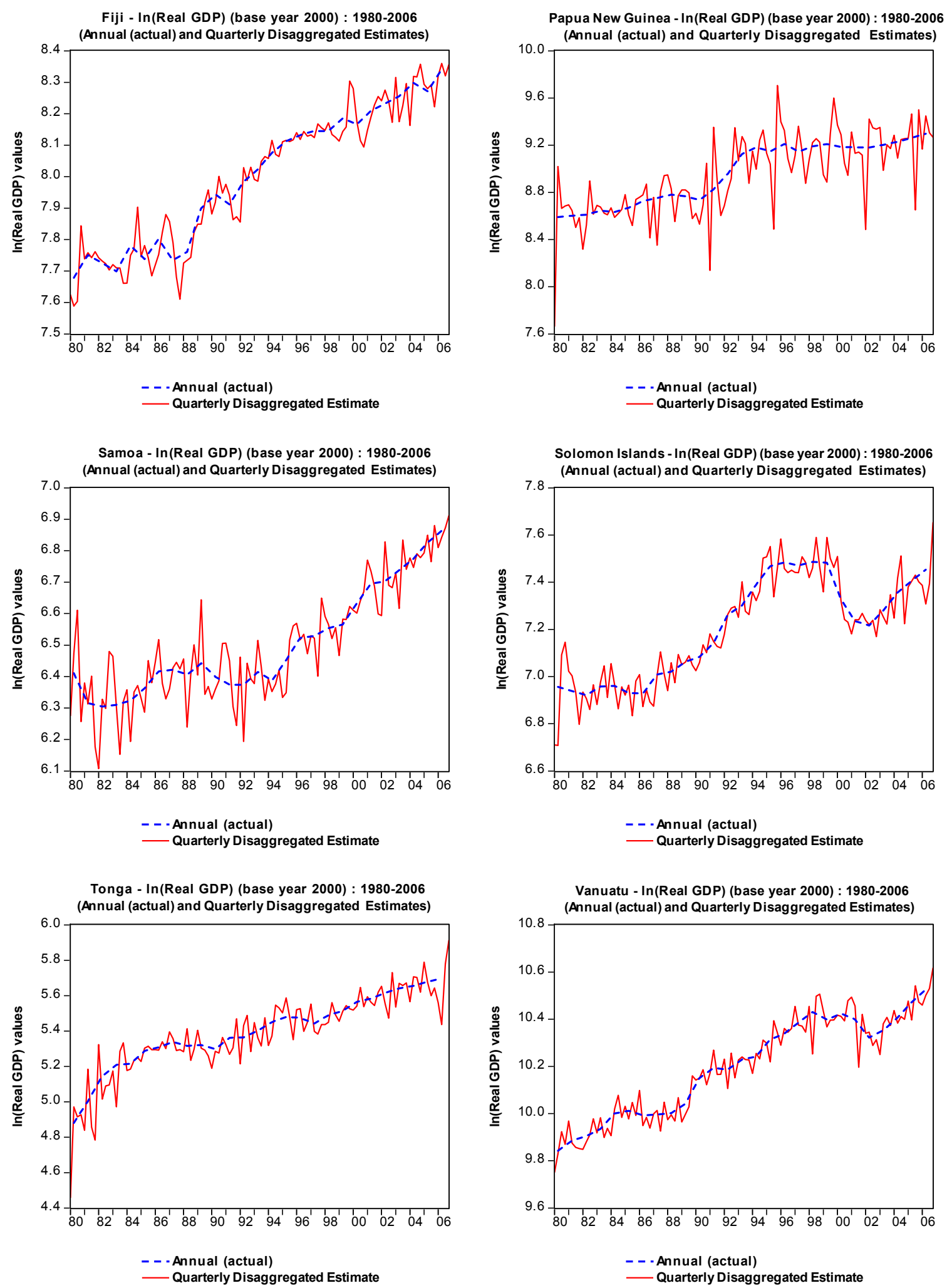